\title{
Cyclooxygenase-2, Drug Target for Anti-Inflammatory Bioactives from Natural Sources
}

\section{Shailasree Sekhar}

Institution of Excellence, Vijnana Bhavana, University of Mysore, Mysuru, Karnataka, India

Corresponding author: Shailasree Sekhar, Scientist, Institution of Excellence, Vijnana Bhavana, University of Mysore, Mysuru-570 006, Karnataka, India, Tel: +91 9480476031; E-mail: shailasree@ioe.uni-mysore.ac.in

Rec date: Aug 18, 2016; Acc date: Sep 07, 2016; Pub date: Sep 12, 2016

Copyright: (c) 2016 Sekhar S. This is an open-access article distributed under the terms of the Creative Commons Attribution License, which permits unrestricted use, distribution, and reproduction in any medium, provided the original author and source are credited.

Citation: Sekhar S (2016) Cyclooxygenase-2, Drug Target for Anti-Inflammatory Bioactives from Natural Sources. Mol Enz Drug Tar 2: 1.

\section{Letter to Editor}

A molecular structure with a capacity for specific interaction with a chemical, the drugs, administered for treatment of a particular disease or its diagnosis is considered a drug target. Mostly enzymes, ion channels, transport proteins, various physicochemical mechanisms, unknown mechanism and receptors are targeted. As almost all biological reactions are the catalytic influence of enzymes, they are considered to be most attractive targets for small molecule drug intervention in human diseases. In human body, reactive oxygen species like superoxide anion and $\mathrm{H}_{2} \mathrm{O}_{2}$ generated in small quantities maintain homeostasis. However, with levels of ROS augmented upon exposure to xenobiotics, leads to lipid peroxidation, triggering the NFKB with upregulation of the pro-inflammatory genes. Further, augmented oxidative stress activates phospholipase A2 mediated aracidonic acid (AA) formation to produce pro-oxidant metabolites viz., as eicosanoids [prostaglandins (PGE2) and hydroxyeicosatetraenoic acids]. Biosynthesis of these is dependent on a single enzyme referred to as cyclooxygenases (COX), COX-1 and -2 mediate many of the classical symptoms of inflammation, viz., pain, swelling, fever etc.)). The nonsteroidal anti-inflammatory drugs, NSAIDS, ibuprofen and asprin, treatment for pain and fever, derive therapeutic effectiveness as anti-inflammatory drugs from inhibition of COX, suffer mechanism-based side effects including gastric and renul ulceration on long-term usage due to inhibition of COX-1 and it was soon clear that all antiinflammatory activity should be associated with inhibition of only COX-2.

With questions raised over the safety of synthetic drugs, an increased screening for antioxidants with anti-inflammatory capacity from natural sources is gaining attention. Advances in technology has allowed screening and identification of bioactives for a single or multidrug therapy and almost $60 \%$ of drugs approved as anti-inflammatory and to treat cancer are being from natural origin. The presence of bioacitves viz., flavonoids, phenolic acids (alkaloids, amines, betalains), terpenoids (e.g., carotenoids) stilbenes, tannins, coumarins, lignans and lignins in plant/parts (viz., roots, leaves, branches/ stems, flowers and fruits) due to their capacity to retard oxidative degradation of lipids, capacity to quench free radicals, and ability to chelate metals graduate them as medicinal plants.

Western Ghats, in India, locally known as the Sahyadri, one of the 34 global biodiversity hotspots runs along the Western Coast covering an area of $159,000 \mathrm{sq} \mathrm{km}$ with reported 500 medicinal plant species used in traditional medicine. Validation of traditional application of a medicinal plant (part) with scientifically executed data is the need of the hour. Thus newer work on medicinal plants with mostly rediscovery of traditional effects at cellular and molecular levels formed centre of my research work. I initiated my journey with compilation of scientific information and pharmacological attributes of medicinal plants of Western Ghats, India for promoting wider acceptance and use of plant based drugs in main stream of medicine.

Studies from my lab have reported screening a spectrum of Western Ghats medicinal plants with a capacity of inhibit COX-2. Buchanania lanzan, Spr. (Anacardiaceae), commonly known as Chironji, has been used for treating ailments viz., to reduce granular swelling; relieve prickly heat; bark gum for treating diarrhea and intercostals pain and leaves as antiophidian. The Ayurvedic pharmacopoeia of India describes oral intake of 5-10 g dried stem bark to cure fevers and inflammatory conditions. In this direction my studies reported significant antioxidant activity with a potential to inhibit human cyclooxygenase-2 in a dose dependent manner. Elaeocarpus tuberculatus Linn. and $E$. serratus Linn. (Elaeocarpaceae) methanol extract of leaves exhibited antiinflammatory capacity with human cyclooxygenase-2 inhibition. Recently, screening and evaluation of $\sim 10^{6}$ bioactives from Eryngium foetidum Linn. by in-silico molecular docking to COX-2, 1PXX, and analysis by FleX X identified caryophyllene oxide in particular as a potent COX-2 inhibitor. The docked pose resembled the orientation similar to that observed with diclofenac ligand. Co-crystallization of the above said bioactive with COX-2 and XRD analysis is an extended study undertaken currently. 